\title{
Health Services in Australia
}

\author{
D. J. R. SNOW
}

Department of Public Health, Perth, Western Australia

Although I am of course familiar with the broad nationwide pattern of health services in my country, I am, as a State rather than a Federal person, much better informed on the details of the health services available in my own state. Therefore, I will deal with the national scene in broad principle rather than in detail.

Before embarking upon any discussion of health services I believe it would be appropriate to consider the essential objectives of any public health administration. When the objectives are clear, the nature of the organizations which are set up to attain these objectives become much more intelligible. I have seen many statements purporting to define these objectives, but there are two which, I believe, best illustrate the approach used in Australia. The first is shown in a statement once made by your own Abraham Ribicoff, one time Secretary of the U. S. Department of Health, Education and Welfare:

The main objects of a Public Health Administration are to keep illness from happening, to keep it from spreading if it does happen, and to keep as many, people as possible as healthy as possible for as long as possible.

Australia's most distinguished medical scientist, Sir MacFarlane Burnet, once wrote in a similar vein:

The aim of medicine in the broadest sense is to ensure that every individual from conception to death enjoys the fullest measure of health and well-being that are allowed by his genetic constitution and by the accidents of life.

These are quite profound statements because their implications extend far beyond the limited borders of infectious disease, which was originally responsible for the establishment of organized public health services. They embrace all the causes of human illness-infective, degenerative, neoplastic, mental, nutritional and even social; and these are the guide-lines along which both the Federal and State Health Services in Australia have developed or are developing.

First, some general description of the constitutional machinery in Australia will be necessary. Aus- tralia is what is called a commonwealth, but for practical purposes it is a federation very similar to the United States of America. It consists of six states and two territories. There is, therefore, the Federal Government (which also administers the two Territories) and the six State Governments-New South Wales, Victoria, Queensland, South Australia, Western Australia and Tasmania.

Each of the seven governments, i.e., the Federal and the six State Governments, has a Minister for Health in charge of health services. Although in the past a distinguished physician has occasionally occupied one of these positions, because of his political involvement and ability, it is usual and general that all Health Ministers are laymen. Each of these Ministers controls an appropriate department. These are variously called Health Departments, Public Health Departments, Departments of Health and Welfare, and even Health Commissions or Health and Hospital Commissions.

The professional administration of these departments is entrusted to a qualified physician who might be called a Director-General, a Commissioner or a Chief Health Officer. He, in turn, is assisted by a wide range of specialist physicians; most have acquired a post-graduate qualification in public health, known in Australia as in England as the D.P.H. This is roughly comparable to the American M.P.H. and involves an entire academic year's full-time study.

\section{Federal Role \\ Quarantine}

The establishment of the Federal Health Service stemmed from the need to exclude dangerous infectious diseases from Australia. Diseases such as smallpox and plague were constant threats to a country newly settled by Europeans with maritime ties, and cholera was endemic in neighboring countries. There were also the less immediate but acknowledged risks of the introduction into Australia of yellow fever and louse typhus. In other words, the earliest Federal Health Service was essentially a quarantine service-established on the basis of meticulous maritime quarantine and supported by a 


\section{HEALTH SERVICES IN AUSTRALIA}

specially trained staff of quarantine medical officers with a chain of quarantine stations strung around the Australian coastline.

Each of these stations occupies a comparatively large area of land and is sufficiently well equipped to accommodate an entire shipload of passengers. Although they are of course not economical to maintain, they are virtually indispensable to the plan of preventing the spread of infection inadvertently brought to the shores of the country. The value of this policy is borne out by the record of these dangerous diseases in Australia.

While smallpox and plague have occasionally gained entry there has been no instance of an outbreak of these infections for over 60 years. To my knowledge, a secondary case of cholera has never occurred in Australia and yellow fever has simply never occurred. In the veterinary area the quarantine service has been instrumental in excluding rabies from the country entirely. This is something of crucial importance. One can imagine what would happen if the cunning wild-dogs or dingoes of Australia were infected with rabies virus which is, as you know, a disease which is inevitably fatal. The spread of rabies among the dingoes would have catastrophic consequences on the sheep industry and possibly on cattle industry as well. More recently, attention has been focussed on foot-and-mouth disease. Our veterinarians are determined to prevent the disaster of the last British epidemic being repeated in Australia. Thus, the Federal Authority's earliest responsibility was the exclusion of diseases such as these from Australia. Indeed, today this is still one of its main commitments.

\section{Coordination}

As the nation developed, however, the responsibilities of the Federal Health Service grew very rapidly. The need for coordination of health policy throughout the country was recognised, and machinery was accordingly set up to facilitate a regular exchange of views among health representatives from all states. A body which is now called the National Health and Medical Research Council of Australia was then formed. Although it is only an advisory body to both the Federal and State Health Ministers through their respective professional officers, it is so important and has such a dominant influence on health policies in Australia that I am compelled to describe it at some length.

This board meets twice a year and has some 18 members including the Health Chief of every state; representatives from the Australian Medical Association, the Australian Dental Association, the learned Colleges (i.e., of Physicians, Surgeons and Obstetricians), the Universities and the nursing profession; and, to ensure that the professionals remain realistic, a prominent businessman is included as well.
The Chairman is Director-General of the Federal Health Service-Sir William Refshauge. He also happens to have the honour of being the current Chairman of the Executive Board of the World Health Organization.

This council is without doubt the most highly respected official health body in the land. It is respected not only by politicians, but also by those in the professions and by the public at large. Rarely is any major health decision taken by either the Federal or State Government without obtaining prior advice of this council, and over the course of many decades there has been little cause to criticise any of its recommendations.

It has three main committees: a Public Health Committee, concerned with matters of public health policy; a Medicine Committee, concerned essentially with clinical and therapeutic medicine; and a Medical Research Committee, of which the main functions are to assess the relative importance of various research projects and to recommend appropriate financial grants for these projects. In addition, it has several lesser committees such as the Epidemiology Committee, the Veterinary Public Health Committee, the Mental Health Committee, the Food Standards and Food Additives Committee, the Dental Health Committee, the Committee on Preventive Medicine in General Practice, the Medical Statistics Committee and even the Traffic Injury Committee.

Persons are appointed to these subsidiary or expert committees because of their specialist knowledge, rather than because of geographical or state considerations. Their fares and other expenses for meetings are met from federal funds.

The range of subjects dealt with by this council are indicated by the designations of its committees; but there are of course ad-hoc or other special subcommittees which are appointed, from time to time, to consider special problems such as smoking or detergents.

This vital coordinating function of the National Health and Medical Research Council at the professional level is supplemented by coordination at the political level through an annual meeting of all Health Ministers. The meeting places, like those of the Council, rotate in turn among the various capital cities. In consequence, although states, under the nation's Constitution, are responsible for public health affairs within their boundaries-and indeed are extremely jealous of their rights-nevertheless there is a very great concordance of administrative action on major health issues. Although the individual systems of administration within the states may differ, and although their methods of implementing various health programmes may vary, there is a basic uniformity of approach which ensures a fairly even standard of public health throughout the country. 


\section{Other Responsibilities}

Apart from the responsibilities of quarantine and coordination, the Federal Health Service has been obliged to assume a number of other major responsibilities over the last 25 years.

One notable commitment has been tuberculosis control. Here, the Federal Authority provides the funds and recommends broad policy, while the states do the work. Tuberculosis has largely been controlled as a consequence of mass miniature radiography, Mantoux testing, subsidised hospital treatment, and tuberculosis allowances to offset hardship.

Immunisation programmes such as Salk (and now Sabin), triple antigen (DPT), and (presently) measles and rubella vaccination-have been, or will be, carried out under an arrangement between the Federal and State Authorities. The Federal Authority provides the material free of charge to the states, which in turn provide the organisation and meet the costs of administration.

Perhaps the most significant feature of the expanded federal role since World War II has been the advent of the Medical Benefits Scheme, the Pensioner Medical Scheme, and the Pharmaceutical Benefits Scheme. These schemes came into operation by federal enactment nearly 20 years ago. The essential principles involved are:

1. The costs of drugs, medical treatment and hospitalization are subsidised by the Federal Government.

2. Individuals and families are encouraged to insure against illness with various benefit funds or insurance agencies in order to supplement the federal subsidy.

3. Individual pharmaceutical preparations (included in an approved list and prescribed by a physician) are obtainable at a net cost of 50 cents to the patient.

The effect of this type of system is that freedom of choice of the doctor is preserved by the patient and the financial burden of ill-health is dispelled.

There are a number of other services provided by the Federal Health Authority such as specialised laboratories, medical and health services to the two Territories, and the maintenance of the only School of Public Health and Tropical Medicine in Australia. However the services I have previously mentioned are perhaps the most important ones, especially when looked at through the eyes of a State Health Administrator.

\section{State Role}

In discussing the general state component of Australia's health services, I shall deal particularly with the health service of Western Australia because, as I inferred earlier, although no one state service is the exact mirror-image of another, the broad pattern is similar. Thus, what might be said about Western Australia could, with reservations, apply to the type of service provided in all states.

The reservations I mentioned might tend to be somewhat Texan in character but this is rather difficult to avoid when one is conscious of the fact that Western Australia is about eight times the size of the United Kingdom, three times the size of Texas, grows the tallest trees and the hardest timber in Australia, produces wild flowers of unexcelled beauty, has nearly the best wool and wheat, has sired some of the fastest milers (Herb Elliot) and swimmers (Garry Agnew) and even billiard players (Bob Marshall) in the world, and is on the eve of becoming perhaps the largest source of high-grade iron ore and nickel ore in the world. There are of course a few disadvantages (such as the pestiferous bush fly or musca sorbens, some desert, rather too much litter and one or two other minor problems) but this is no time to dwell on such matters.

\section{Immunisation}

The fact is that Western Australia has the best polio vaccination record of any other comparable community. Diphtheria and whooping cough are virtually unknown and tetanus is very rare. You may be interested in the system that underlies this achievement. Quite simply it is based on the principle of taking a free service to the child by means of itinerant mobile clinics to supplement the proportion of private immunisations carried out by family doctors.

More than half of Western Australia's population is concentrated in and around Perth (the place that American news media were kind enough to label "The City of Light" because everyone turned their lights on as a neighbourly gesture to John Glenn on his first orbit). The remainder of the population, however, is scattered over a multitude of small towns and settlements, some without doctors, and a regular visiting service is essential if the maximum levels of immunity are to be sustained.

At any rate, the fact is that some 50 percent of immunisations are conducted by private practitioners and the other 50 percent by State Health Service officers. In other words, both private and official agencies contribute to the maintenance of child health in a spirit of partnership rather than competition.

\section{Infant and Child Health}

An extension of this principle applies in the broader area of infant and child health generally. The Health Department's Infant Health Nursing Service with its network of Infant Health Centres cooperates closely with family doctors and with the University Department of Child Health, in ensuring that deviations 


\section{HEALTH SERVICES IN AUSTRALIA}

from normal are detected early and remedied promptly.

The approach to the control of maternal mortality may be of special interest because it was patterned on the Minnesota system some ten years ago and has worked well in practice. By statute, any maternal death must be reported immediately to the Health Commissioner. A specialist obstetrician, invariably from the University department of obstetrics, is empowered to investigate all the circumstances in detail. He prepares a summary of the salient features, omitting all reference to names, dates and places. His summary is presented to and considered by a panel of experts legally constituted as a committee, with specific specialists coopted where necessary.

This committee determines the cause of the death and endeavours to identify avoidable factors if any. The chairman, normally a professor of obstetrics, who is the only person other than the Health Commissioner entitled by law to know the names involved, communicates confidentially to the doctor concerned with the intention of helping him to avoid any similar errors of judgement in the future. In other words, the essential approach is educative rather than punitive. Because this is so, answers to the investigator's questions are perfectly frank and uninhibited by the spectre of legal action; and there is whole-hearted cooperation and support from the medical profession at large.

\section{Welfare of the Aged}

We are closely involved with promoting the welfare of the aged and with ensuring that they remain independent or semi-independent for as long as possible. There is a voluntary agency, known as The Meals on Wheels Organisation, with which the Health Commissioner is associated and which receives some financial assistance from the State Government. With the aid of honorary voluntary drivers, using their own cars, a balanced hot meal is delivered once a day, for a nominal fee, to the home of any aged person who needs it. Another voluntary agency assisted by the State provides a home nursing service.

The Federal Government's Pensioner Medical Service enables pensioners to receive free medical attention from private doctors. However, the State Health Department maintains a geriatric service headed by a senior specialist in internal medicine who holds a University appointment as well. $\mathrm{He}$ and his aides provide a consultative service to general practitioners and to the major hospitals, and they are medically responsible for the surveillance of old people within Perth's two main institutions for the aged. One of these is most appropriately named Sunset.

One of the comparatively recent developments has been the growing number of cottage groups that have been established for the aged by religious organisations of many denominations. Capital costs are subsidised both by the Federal and State Authorities, and units are usually sold to appropriate applicants on a life-time-lease arrangement.

\section{Health Education}

We recognise health education as an indispensable aid in achieving the voluntary cooperation of the public, and we recognise its support for various health measures. Accordingly we have an organisation called the State Health Education Council, which operates under statute and receives a substantial grant to finance its activities. Apart from a secretariat including full-time health educators, it comprises some 17 honorary members drawn from professional associations, from various influential citizens' organisations, and from the several news organisations. In this way an adequate number of pipe-lines for the dissemination of information are maintained.

Short courses in health education are conducted, for groups such as the Red Cross and for interested individuals, so that the pool of potential field workers can be expanded. Special instruction is offered to teacher-trainees and to nurses. We have found health education, implemented in this way, to be extremely helpful in promoting immunisation programmes, the acceptance of fluoridation, the understanding of venereal disease, better food handling, insect control and many other projects. Although there is a level of routine commitments, it has been customary to expend a major effort for a limited time on some specific project. At the present an intensive drug education programme is under way. Although this problem has not yet reached major proportions in our part of the country, we feel that young people should be informed of the nature, effects and dangers of drugs.

Apart from general health education, education for safety is carried out by an organisation known as the National Safety Council. It has four divisions concerned respectively with road safety, industrial safety, home safety and water safety. Officers of the Health Service are associated with this organisation and are particularly active in the field of home safety.

Other areas of public education which are rapidly being developed are cancer education, dental health education and mental health education.

\section{Other State Responsibilities}

Other potential health problems which I have not yet mentioned are those relative to drinking water supplies, the disposal of refuse, clean air and the control of radioactive substances, pesticides, and therapeutic "poisons."

So far as water is concerned the State Health Service has little direct responsibility, other than to ensure of course that these supplies are safe. The collection, treatment and supply of potable water is 


\section{J. R. SNOW}

the responsibility of two other major government agencies; but a close liaison exists with the Health Service and the results of the regular routine chemical and bacteriological tests are kept under surveillance by a committee comprising health officers, engineers, chemists and other specialists.

Radioactive substances, clear air, pesticides and poisons are all overseen by the State Health $\mathrm{Au}$ thority either under specific statutes or regulations promulgated under the Health Act. In essence, they involve the usual system of licensing, permits and inspections and would only be of passing interest to you.

\section{Flying Doctor Service}

I have no intention, nor would there be sufficient space here, to describe the nature of the services in Western Australia that have to do with curative medicine; but there is at least one service in which people in many parts of the world are interested. I refer to the Flying Doctor Service. This is, in effect, a service organized and maintained by an association of private citizens. It is financed partly by public subscription, partly by the various governments, and partly through regular subscriptions from members.

In my state the Flying Doctor agency provides the light aircraft required and employs trained pilots and radio operators, but the State Health Service provides the doctors. The latter are government salaried medical officers based on several towns along our North West Coast, and the radio bases are usually located at or very close to the hospitals where these doctors work.

Each Flying Doctor network comprises a radio base associated with a doctor and a hospital and serves an area of up to 200 miles in radius. There may be some 30 or more "subscribers" dispersed over a wide, sparsely populated area. Each of these subscribers is equipped with a standard radio transceiver and a Flying Doctor medicine chest containing most of the drugs and dressings likely to be required in medical or surgical emergencies. The network is also used for the transmission of private messages and telegrams; at least two regular daily radio sessions are set aside for this purpose. Emergency calls can, of course, be made at any time.

When a doctor is called to the base he is confronted with the task of, in effect, making a diagnosis by telephone. His task is, however, assisted by the use of a chart which divides the human body into a number of designated segments. This, together with a description of the symptoms, enables him to make a fair assessment of the location, intensity and nature of the disorder. Having made a provisional diagnosis he may decide to do one of three things.

First, he may decide to leave the patient where he is and recommend the administration of one of the numbered preparations in the medicine chest. Second, he might decide to send a plane out to collect the patient and bring him into hospital. Finally, he might decide to go out himself with the plane, render whatever emergency medical aid may be called for, and accompany the patient back to the hospital base.

This service is extremely popular and provides a vital link between cattle stations, sheep stations, missions and other isolated settlements in what can be a fairly harsh environment commonly known as the Outback. Although the function of this service is primarily to provide emergency treatment, it is occasionally used for preventive purposes such as scheduled immunisation programmes or infant welfare purposes. 